\title{
VARIAÇÃO DA UMIDADE RELATIVA DO AR NO CORAÇÃO DA FLORESTA AMAZÔNICA, UM ESTUDO DE CASO NO MUNICÍPIO DE COARI (AM) DURANTE O ANO DE 2015
}

\author{
George Pereira Reis ${ }^{(\mathrm{a})}$ :Elias de Oliveira Moraes ${ }^{(\mathrm{b})}$
}

\author{
${ }^{(a)}$ Professor do Instituto Federal de Educação, Ciência e Tecnologia do Amazonas- IFAM/ \\ george.reis@ifam.edu.br \\ (b)Professor do Instituto Federal de Educação, Ciência e Tecnologia do Amazonas- IFAM/ \\ elias.moraes@ifam.edu.br
}

\section{Eixo: CLIMATOLOGIA EM DIFERENTES NÍVEIS ESCALARES: MUDANÇAS E VARIABILIDADES}

\begin{abstract}
Resumo/
O vapor de água na atmosfera é de suma importância na formação de nuvens, precipitação, manutenção da temperatura e ajuda até mesmo no bom funcionamento da saúde humana, a maneira mais difundida de se medir a quantidade de vapor de água na atmosfera é a umidade relativa do ar, expressa em porcentagem. A região amazônica apresenta o clima equatorial, durante o ano as temperaturas se mantem elevadas e as chuvas caem com abundância, essas características fazem dessa área uma das mais úmidas do globo. Partindo desse ponto, o trabalho teve como objetivo analisar a variação da umidade relativa do ar no município de Coari (AM) durante o ano de 2015, no qual se verificou valores de $27 \%$ de umidade relativa do ar.
\end{abstract}

Palavras chave: ar seco, floresta, Coari.

\section{Introdução}

A maior extensão de floresta quente úmida do globo, a Amazônia apresenta uma notável variedade de fauna e flora, esse tapete verde que se estende por mais de 5 milhões de $\mathrm{km}^{2}$ formada por uma complexa rede de rios, igarapés e lagos que juntos formam a maior bacia hidrográfica da Terra, o rio Amazonas com 6.992,06 quilômetros de extensão é o maior rio do mundo. A grande disponibilidade de água na superfície e a floresta fazem com que a região amazônica apresente elevados totais pluviométricos durante o ano, outro importante fator que contribui muito na formação climática da região é o fato que metade da região estar localizada em baixas latitudes, ou seja, o clima é equatorial. No Brasil, este tipo de clima é predominantemente da porção norte, compreendida pelos estados do Amazonas, Pará, Acre, Rondônia, Amapá, e parte de Roraima, Tocantins, Mato Grosso e Maranhão. Nos domínios morforclimáticos do Brasil Ab' Sáber (2003) nomeia essa região de o macrodomínio da Amazônia brasileira, segundo o mesmo trata-se de um gigantesco domínio de terras baixas florestadas, disposto em anfiteatro, enclausurado entre a grande barreira imposta pela cordilheira dos Andes, pelas bordas do planalto central brasileiro e do planalto das Guianas. De sua posição geográfica resulta uma fortíssima entrada de energia solar, acompanhada de um abastecimento quase que permanente de massas de ar úmido e grande estoque de nebulosidade. Segundo Mendonça e Danni-Oliveira(2007) A temperatura média anual desse tipo de climático situa-se entre $24^{\circ} \mathrm{C}$ e $26^{\circ} \mathrm{C}$, em termos de 
pluviosidade, apresenta os maiores totais pluviométricos do país. Em algumas áreas, o total médio anual ultrapassa os $3.000 \mathrm{~mm}$, ao passo que outras não passam de $1.600 \mathrm{~mm}$.

Boa parte das chuvas que caem sobre a Amazônia é gerada pela própria floresta, através daevapotranspiração. Em seus estudos sobre a floresta e o clima da Amazônia, Nobre (2014) afirma que uma árvore de grande porte podebombear do solo e transpirarmais de mil litros de água num único dia. A Amazônia sustenta centenas debilhões de árvores em suas florestas, liberando enormes quantidades de vapor de água para atmosfera. De acordo com Cavalcanti et al (2009) outro importante indutor de precipitações na região é Zona de Convergência Intertropical - ZCIT provoca chuvas de janeiro a junho tendo maior influência nos meses de março/abril. A ZCIT é uma banda de nuvens que circunda a faixa equatorial do globo terrestre, formada principalmente pela confluência dos ventos alísios do hemisfério norte com os ventos alísios do hemisfério sul.

De acordo com Mendonça e Danni-Oliveira (2007) a umidade relativa do ar é certamente o medida mais conhecido para representar a presença de vapor de água na atmosfera. Ela mostra em porcentagem a quantidade de vapor de água contida no ar, sob a temperatura em que se encontra. Para Ayoade (1998) a umidade relativa é a razão entre o conteúdo real de umidade de uma amostra de ar e quantidade de umidade que o mesmo volume de ar pode conservar na mesma temperatura e pressão quando saturado.

O município de Coari pertencente ao estado do Amazonas localizado nas coordenadas de 04 05' 06" de latitude sul e $63^{\circ} 08^{\prime} 29^{\prime \prime}$ de longitude oeste (figura 1), junto aos 20 municípios compõe a mesorregião centro amazonense, a região do estado mais povoada e populosa, onde estar localizada Manaus e as maiores cidades do interior do Amazonas, Parintins, Manacapuru, Itacoatiara e Coari com 83 mil habitantes (IBGE, 2016).Com uma área territorial de $57970.783 \mathrm{~km}^{2}$ Coari é destaque no cenário econômico nacional, pois é segundo município brasileiro que mais produz gás como também é a segunda zona produtora de petróleo em terra (PETROBRAS, 2016). 


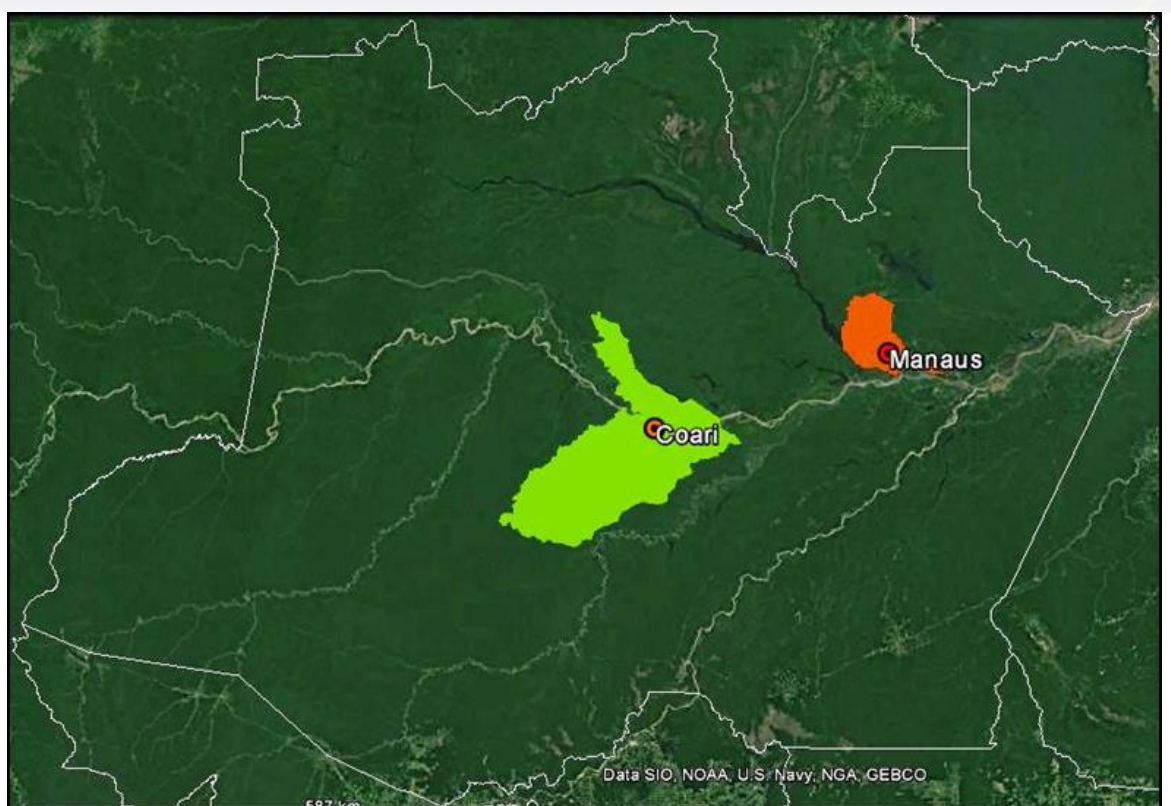

Figura 1 - Localização do município de Coari no Estado do Amazonas. Fonte: Google Earth

Conforme Nimer (1989) a Amazônia possui desde a inexistência de mês seco até a existência de 3 meses secos. O centro amazonense não é a região do estado com os maiores totais pluviométricos, apresentando em sua grande parte de dois a três meses de seca, segundo o Serviço Geológico do Brasil (CPRM, 2011) a região apresenta totais pluviométricos anuais que variam de $2100 \mathrm{~mm}$ a $2600 \mathrm{~mm}$. Coari apresenta uma pluviometria aproximadamente de $2200 \mathrm{~mm}$ anuais com três meses de baixa precipitação, julho, agosto e setembro, esse período popularmente é conhecido como verão, já que as chuvas reduzem bastante e as temperaturas se elevam com facilidade, a cidade de Coari estar situada às margens do rio Solimões e do lago Coari essas características locais lhe confere uma cidade inserida no coração da floresta amazônica com uma elevada umidade relativa do ar durante o ano, entretanto de julho a setembro a umidade relativa do ar tende a declinar. A baixa precipitação e as elevadas temperaturas causam inflência na quantidade de vapor de água presente na atmosfera. Partindo desse pressuposto o presente estudo teve como objetivo analisar a variação da umidade relativa do ar durante o ano de 2015 no município de Coari no Amazonas.

\section{Metodologia de Trabalho}

Segundo recomendações da Organização Mundial de Saúde - OMS níveis abaixo de 60\% de umidade relativa do ar não são favoráveis para a saúde (SGE-SP, 2017).Quando a umidade relativa do ar fica entre $20 \%$ e $30 \%$ é classificada como estado de atenção (CEPAGRI/UNICAMP, 2008). O trabalho teve como objetivos verificar quantos dias do ano o município registrou umidade relativa do ar abaixo de $60 \%$, identificar os meses que tiveram o maior número de dias com baixa umidade relativa do ar, constatar as horas do dia em que a umidade atingiu os mais baixos índices e relacionar a baixa umidade do ar com o défice de chuvas e a atuação do El Niño. Segundo Steinke (2012) o ser humano 
é muito sensível à variação da umidade do ar, isso porque a pele humana elimina, por meio da transpiração, a água que o organismo produz. A baixa humidade relativa do ar é uma situação perigosa para a saúde humana, pois pode provocar desidratação e o aumentonos casos de doenças respiratórias.

Para o desenvolvimento dessa pesquisa foram obtidos dados de umidade relativa do ar horário disponibilizados pela rede de estações meteorológicas automáticas do Instituto Nacional de Meteorologia - INMET. Os dados de precipitação mensal do período estudado também foram analisados, a fim de comparar com a média histórica anual e detectar alguma anomalia negativa de precipitação, para que assim fosse estabelecida uma relação entre a precipitação e os níveis de umidade relativa do ar.

Essas informações são disponibilizadas gratuitamente no site do INMET. A estação meteorológica automática de Coari está instalada no terminal aquaviário da Petrobras a $4^{\circ}$ 09'48.3' de latitude sul e $63^{\circ} 14$ '53.22" de longitude oeste com altitude média de 34 metros, aproximadamente a $15 \mathrm{~km}$ da zona urbana de Coari, foram coletados dados de umidade relativa do ar durante todo o ano de 2015, sendo que para o estudo foi tabulados apenas a menor umidade relativa do ar do dia e assim como a hora correspondente.

\section{Resultados e Discussão}

A análise dos dados demostraram que durante o ano de 2015, o município de Coari teve 199 dias em que a umidade relativa do ar manteve-se baixa em determinadas horas do dia. No geral os períodos que apresentaram a menor taxa de umidade relativa do ar são das $13 \mathrm{~h}$ às $14 \mathrm{~h}$. Todos os meses do ano registraram umidade relativa do ar abaixo de $60 \%$, entretanto o mês de agosto teve 29 dias e setembro com 28 dias, seguidos por julho com 25 dias, outubro com 24 dias e novembro com 19 dias, como pode ser observado na figura 2. Em relação aos menores índices de umidade relativa no ar no município foram registrados no mês de setembro quando no dia 10 às $14 \mathrm{~h}$ a umidade relativa do ar caiu pra $27 \%$ no dia seguinte foi registrada a segunda menor taxa de umidade relativa do ar do ano $28 \%$ também às $14 \mathrm{~h}$.

Setembro foi o mês mais crítico, tiveram seis dias em que a umidade relativa do ar caiu pra estado de atenção, os outros casos foram no dia 23 e 24 a umidade caiu pra $29 \%$ no primeiro caso foi às $15 \mathrm{~h}$ e outro às $14 \mathrm{~h}$, no dia 25 a umidade caiu pra $30 \%$ às $14 \mathrm{~h}$ e no dia 27 a umidade atingiu $29 \%$ às $13 \mathrm{~h}$. Setembro foi o único mês a registrar estado de atenção devido à baixa umidade relativa do ar. Essa condição pode estar associada à atuação do El Niño em 2015. De acordo com Cavalcant et al (2009) os fenômenos El Niño e La Niña exercem forte influência na variabilidade climática da região, causando sérios problemas ambientais, sociais e econômicos relacionados à seca e as enchentes. No geral, em anos de El Niño as temperaturas e ficam mais elevadas que o normal e as anomalias 
XVII Simpósio Brasileiro

de Geografia Fisica Aplicada

I Congresso Nacional

de Geografia Física

\section{OS DESAFIOS DA GEOGRAFIA FÍSICA NA FRONTEIRA DO CONHECIMENTO \\ Instituto de Geociências - Unicamp \\ Campinas - SP \\ 28 de Junho à 02 de Julho de 2017}

negativas de precipitação são mais intensas, favorecendo o aumento de incêndios florestais. Durante a La Niña, a Amazônia tende a ser mais úmida e chuvosa.

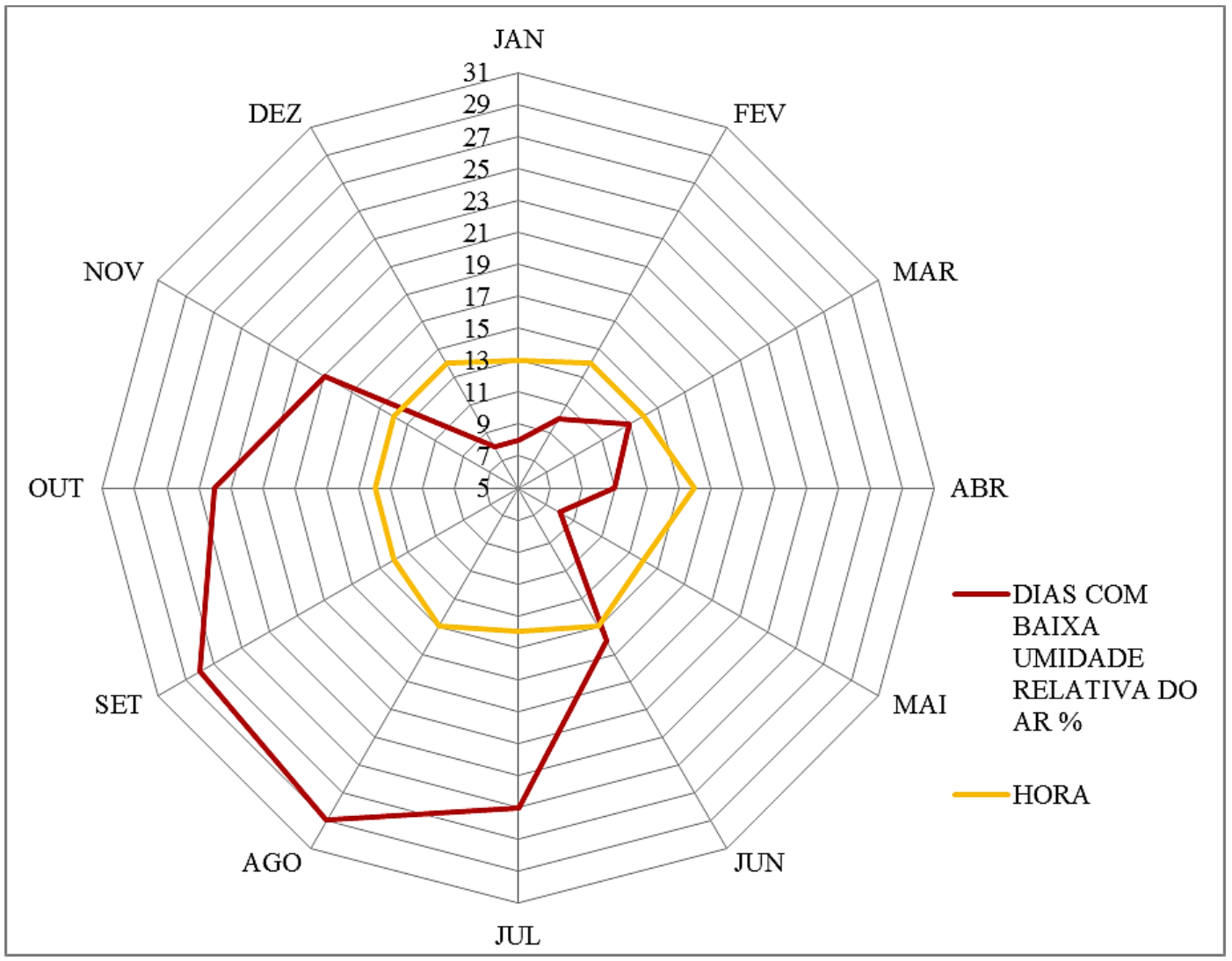

Figura 2 - Dias e hora com menor umidade relativa do ar no município de Coari-AM no ano de 2015. Fonte: INMET

O ano de 2015 foi marcado pela atuação de um dos El Niño mais forte desde que se tem registro, sua intensidade foi comparada com os dos anos de 1997-1998. Conforme o Centro de Previsão e Estudos Climáticos (CPTEC, 2015) o El Niño se configurou no Pacífico equatorial em março-abril, porém ainda com fraca intensidade o trimestre maio, junho e julho o El Niño foi caracterizado de fraca a moderada intensidade, no trimestre agosto, setembro e outubro o El Niño evolui para a categoria forte e seus efeitos começaram a serem sentidos de forma mais acentuada no Brasil, a região Sul teve chuvas acima da média. O contrário foi observado na região Norte, e no Nordeste a seca se prolongava pelo quarto ano consecutivo. Entre novembro e dezembro de o El Niño atingiu sua máxima intensidade e alcançou a categoria muito forte gravando o quadro de seca nas regiões Norte e Nordeste (CPTEC, 2015). Como consequência as chuvas ficaram abaixo do esperado para o período em grande parte do estado do Amazonas, abrangendo a mesorregião do centro amazonense, onde se localiza o município de Coari (INMET, 2015). Na tabela I é possível perceber como a pluviometria mensal ficou abaixo da média para o período, setembro foi o mês com o menor total pluviométrico do ano houve apenas dois dias com chuva que totalizou apenas 5 milímetros. Vale ressaltar que conforme os dados disponibilizados pela estação meteorológica automática do INMET a maior temperatura registrada no 


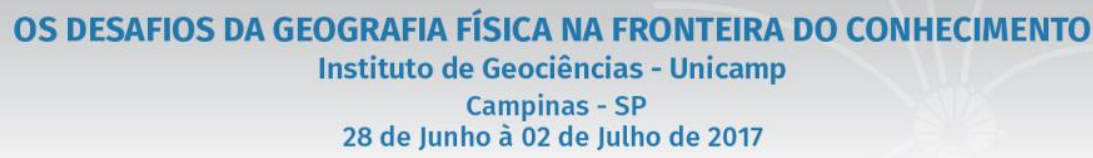

município não ultrapassou os $36^{\circ} \mathrm{C}$, as mais altas temperatura foram também observadas no mês de setembro, justamente quando a umidade relativa do ar ficou abaixo de $30 \%$.

Tabela I - Precipitação observada durante o verão amazônico em Coari (AM). Fonte: INMET

\begin{tabular}{|c|c|c|}
\hline MÊS & $\begin{array}{c}\text { PRECIPITAÇÃO } \\
\text { OBSERVADA }- \\
2015(\mathrm{~mm})\end{array}$ & $\begin{array}{c}\text { MÉDIA PARA O } \\
\text { PERÍODO }(\mathrm{mm})\end{array}$ \\
\hline Julho & 20 & 78 \\
\hline Agosto & 23 & 75 \\
\hline Setembro & 5 & 87 \\
\hline Outubro & 109 & 166 \\
\hline Novembro & 146 & 196 \\
\hline
\end{tabular}

O período de seca se prolongou para os meses de outubro e novembro, ou seja, foram cinco meses com chuvas abaixo da média, e altas temperaturas favorecendo incêndios de grandes proporções em grande parte da floresta amazônica brasileira, dados do Instituto Nacional de Pesquisas Espaciais (INPE, 2016) mostra que no Amazonas os meses de setembro e outubro bateram todos os recordes de focos de incêndios, só o mês de setembro foram contabilizados 5.900 mil focos de incêndios em outubro foram 2.600 focos de incêndios, Manaus e várias outras cidades do interior ficaram encobertas pela uma nuvem de fumaça praticamente o dia inteiro, como foi o caso da cidade de Coari. Nos anos de 1997/1998 também marcados pela atuação de um intenso El Niño conforme Cavalcanti et al,(2009) houve seca na região amazônica, o fenômeno influenciou na redução dos valores de precipitação e gerou impactos no ecossistema. Um desses efeitos foi à redução da umidade e consequente aumento da inflamibilidade da floresta.

Diante dos fatos nota-se que o forte El Nino de 2015, que começou em março de 2015 e intensificouse em agosto, atingindo sua intensidade máxima nos meses de novembro/dezembro,influenciou os padrões de precipitações e temperaturas da região favorecendo inúmeros incêndios, esses eventos aliados geraram impactos diretos na umidade relativa do ar, o que fez com que durante vários dias consecutivos o ar ficasse quente e seco em determinados momentos do dia.

\section{Conclusões/Considerações finais}

O verão amazônico de 2015 no município de Coari no interior do Amazonas, não foi um verão típico, chuva abaixo da média, temperaturas elevadas e a floresta Amazônica em chamas por diversos dias, interferiram negativamente nos índices de umidade relativa do ar. Nem mesmo a grande disponibilidade de água superficial presente nos, rios, igarapés e lagos, conseguiu mantém bons níveis de umidade relativa do ar na região. Por irresponsabilidade humana inúmeros incêndios atingiram grandes áreas da floresta Amazônica, a floresta que contribui para a manutenção da alta umidade do ar na região estava colaborando para baixar ainda mais os níveis de umidade relativa do ar. A região 
conhecida pelas constantes chuvas, nos meses de agosto, setembro e outubro de 2015 se transformou na Amazônia da fumaça e do fogo.

Ainda que o fenômeno climático El Niño tenha afetado os padrões de umidade da região, não se pode descartar a participação dos moradores locais para o agravamento da situação, já que a maioria dos incêndios ocorridos no período foi ocasionada de forma criminosa.A previsão de formação do El Niño é feita com meses de antecedência, importantes centros de pesquisas climáticas internacionais e nacionais, alertavam que em 2015 teríamos um El Niño de forte intensidade, com energia capaz de causar grandes impactos, ambientais, econômicos e sociais. Mesmo sabendo que o El Niño costuma provocar seca no norte do Brasil, e que nessa condição a floresta estaria mais vulnerável as queimas, a prevenção e fiscalização dos os órgãos responsáveis não foram eficazespara evitar os incêndios na região, que consequentemente contribuíam para baixar os níveis de umidade relativa do ar no município de Coari.

Para o município de Coari que estar inserido no coração da floresta amazônica, cercado por rios, lagos e igarapés, a baixa umidade relativa do ar é uma situação atípica que merece mais estudos e pesquisas a cerca da temática, a fim de estabelecer padrões de umidade relativa do ar durante as estações do ano e a influência de fenômenos como El Niño, La Niña e a participação das atividades humanas na região.

\section{Bibliografia}

AB' SABER, AZIZ. Os domínios de natureza no Brasil: potencialidades paisagísticas. 7.ed. São Paulo: Ateliê Editorial, 2003.

AYOADE, J. O. Introdução a climatologia para os trópicos. Tradução de Maria Juraci Zani dos Santos; revisão de Suely Bastos; coordenação editorial de AntonioChristofoleti. $5^{\text {a }}$ Ed. Rio de Janeiro: Bertrande Brasil, 1998.

CAVALCANTI, I. F. A.; FERREIRA, N. J.; SILVA, M. G. A. J.; DIAS, M. A. F. S. Tempo e Clima no Brasil. São Paulo: Oficina de Texto, 2009 .

CEPAGRI/UNICAMP. Escala psicrométrica Unicamp para indicação de níveis de umidade relativa do ar prejudiciais à saúde humana. 2008. Disponível em: http://www.cpa.unicamp.br/artigos-especiais/umidade-do-arsaude-no-inverno.html. Acesso em: 13 de janeiro de 2017.

CPRM. Levantamento da geodiversidade projeto atlas pluviométrico do Brasil: isoietas anuais medias, período 1977 a 2006, 2011. Disponível em: http://www.cprm.gov.br/publique/Hidrologia/Mapas-e-Publicacoes/AtlasPluviometrico-do-Brasil-1351.html. Acesso em 14 de outubro de 2016.

CPTEC. Infoclima mensal, 2015. Disponível em:http://infoclima1.cptec.inpe.br/. Acesso em 5 de janeiro de 2017.

IBGE Cidades, 2016. Disponível em: http://cidades.ibge.gov.br/v3/cidades/municipio/1301209. Acesso em 29 de dezembro de 2016.

INMET - Dados das estações automáticas- Gráficos. Disponível em: http://www.inmet.gov.br/portal/index.php?r=home/page\&page=rede_estacoes_auto_graf Acesso em: 13 de dezembro de 2016.

INMET- Desvio de Chuva Acumulada Total Trimestral (mm), 2015. Disponível em: http://www.inmet.gov.br/portal/index.php?r=clima/desvioChuvaTrimestral. Acesso em 23 de março de 2017. 
INPE - Programa Queimadas, 2016. Disponível em: http://www.inpe.br/queimadas/. Acesso em: 19 de dezembro de 2016.

MENDONÇA. F. ; DANNI-OLIVEIRA. I. M. Climatologia: noções básicas e climas do Brasil. São Paulo: Oficina de Textos, 2007.

NIMER, EDMON. Climatologia do Brasil. 2.ed. Rio de Janeiro: IBGE, 1989.

NOBRE, ANTONIO DONATO. O Futuro Climático da Amazônia:Relatório de Avaliação Científica. São José dos Campos, SP, ARA: CCST-INPE: INPA, 2014. Disponível e: file:///C:/Users/Georgep/Downloads/FuturoClimatico-da-Amazonia.pdf. Acesso em: 03 de novembro de 2016.

PETROBRAS. Urucu: completamos 30 anos na Amazônia com gestão responsável, 2016. Disponível em:http://www.petrobras.com.br/fatos-e-dados/urucu-completamos-30-anos-na-amazonia-com-gestaoresponsavel.htm. Acesso em 22 de março de 2017.

SGE- SP. Umidade relativa do ar, 2017. Disponível em: http://www.cgesp.org/v3/umidade-relativa-do-ar.jsp. Acesso em: 13 de janeiro de 2017.

STEINKE, ERCÍlIA TORRES. Climatologia Fácil. São Paulo:São Paulo, Oficina de textos, 2012. 